Article

\title{
Spatial-Temporal Heterogeneous Evolution of Haze Pollution in China as Deduced with the Use of Spatial Econometrics
}

\author{
Jian Hou $\odot$, Shuang Zhang, Hongfeng Song * and Fengshu Li $®$ \\ School of Economics and Management, Beijing Forestry University, Beijing 100083, China; \\ houjian1128@bjfu.edu.cn (J.H.); bljgzs_work@bjfu.edu.cn (S.Z.); lifengshujiayou@126.com (F.L.) \\ * Correspondence: songhf@bjfu.edu.cn; Tel.: +86-139-1132-6758
}

Received: 6 November 2019; Accepted: 3 December 2019; Published: 10 December 2019

\begin{abstract}
Haze Pollution, consisting essentially of $\mathrm{PM}_{2.5}$ and $\mathrm{PM}_{10}$, has been arousing wide public concern home and abroad. It has become a universal urgency for atmospheric researchers, governments, organizations, institutions, and the general public to conduct corresponding actions. Therefore, this paper aims to explore the institutional distribution and the regional evolution trend of path characteristics of haze pollution in China under the spatial-temporal heterogeneity on the basis of spatial econometrics, by incorporating the spatial element into the framework of the Multiple Influencing Factors mechanism. The results show that it has been abating under the governance year by year, though with a decreasing intensity; the major polluted regions have been moving from the East to the central and western area; there is significant spatial autocorrelation among the highly polluted area, but the effective local regulations of les- polluted regions do not impact the neighboring regions correspondingly; among the impacting factors, industrial structure, energy intensity, and traffic pollution have a significant Positive Impact on haze pollution, and the level of urbanization has a Negative Impact, while economic growth and innovation performance have no significant Positive Impact and are both weak in promotion. This research, theoretically and practically, offers reference for the Chinese government to integrate regional effective systems into multiregional diversified environmental governance, so as to realize its Green Ecology Transformation Development Strategy.
\end{abstract}

Keywords: haze pollution; path characteristics; spatial-temporal evolution; heterogeneity; China

\section{Introduction}

Haze pollution, as a global environment issue, has brought severe challenges to human health, socioeconomic development, and the global ecosystem. Especially in China, it has been a prominent issue facing our government and the public. In 2013, sudden large-scale haze pollution emerged in such regions as Beijing, Tianjin, and Hebei province. Air pollution thus became the core issue of environmental control, and it achieved remarkable regulatory effect in recent years [1]. The Assessment Report on Environmental Air Quality Management in China (2018) pointed out that, since the full implementation of the Ten Measures for Air, the coordinated response to climate change had been effectively promoted. By the end of 2018, China had fulfilled the international commitment to reduce the emission intensity of per unit GDP by $40 \%-45 \%$ in advance of 2020 , and the haze pollution control had achieved considerable success. However, it is noteworthy that the latest data from the National Urban Air Quality Report in February 2019 show that the proportion of days with excellent and good atmospheric quality decreased by 2.3 percentage points, while the proportion of days with severe pollution and above increased by 2.2 percentage points in February 2019 compared with the same period last year. At present, the effect of haze pollution governance in China has gradually slowed 
down, or there even appeared reverse growth in pollution. It can be seen that haze governance at the national level is still the most important approach to promote environmental protection and further improve the quality of residents' lives [2].

The level of haze pollution depends largely on the economic and social agglomeration of human living and social development [3]. Besides the complex path characteristics, the agglomeration also includes the impacts of population density and industrial development on the path selection of haze pollution [4], and the differential effect of multidimensional factors such as investment in environmental regulation, technological development, and innovation on its path [5].

There is significant spatial-temporal heterogeneity in haze pollution level. On the one hand, the agglomeration effect of population, industry and other factors caused by economic production activities leads to significant differences in the spatial distribution of haze pollution [6]. On the other hand, the agglomeration promotes the spillover of production factors such as technology and capital [7], which has a substantial impact on the environmental problems of the region gradually, thus resulting in significant differences in time span for haze pollution [8]. As one of the core indicators of governance, haze pollution level is very important for regional environmental quality assessment. So what is the spatial-temporal heterogeneity of haze pollution like? What are the characteristics of the impact path and where they differ from one another through the indicators of this spatial-temporal heterogeneity? Which factors are affecting the regional haze in the economic and social development activities? To answer these questions, this paper systematically digs into a few researches on haze pollution path in the field, analyses the characteristics of haze pollution development in the key stage of Chinese environmental governance under the evolution of spatial heterogeneity, explores the appropriate haze control path, and constructs a feasible diversified environmental governance path system.

This paper is organized as follows. Section 2 provides an overview of the related literature. Section 3 presents the methodology and empirical specifications, as well as the estimation variables and our database. Section 4 discusses the haze pollution path, spatiotemporal heterogeneity, and structural distribution. The empirical results and discussions about spatial econometric analysis of the effects of diversified factors on haze pollution path characteristics are presented in Section 5. Finally, Section 6 provides conclusions and recommendations.

\section{Literature Review}

The research on the characteristics of haze pollution is mainly divided into two key fields: natural science and social science. Scholars from natural science generally define haze pollution as a disastrous weather phenomenon. The composition, structure, and spatial agglomeration effect of the path characteristics of haze are analyzed from the professional perspective such as chemistry, meteorology, geography, etc. [9]. In the traditional field of chemistry, the focus is on solving the problems of the composition, characteristic factors, and observation indicators about haze, which is based on the atmospheric chemistry of atmospheric dynamics processes. For example, Zhang discussed the relationship between the Peroxyacetyl Nitrate pollution (PAN) and other pollutants (such as $\mathrm{O}_{3}$ and $\mathrm{PM}_{2.5}$ ) in winter atmospheric dynamics processes of China; and Pan studied the important role of nitrate in haze formation. At the same time, Han discussed the composition of haze pollution based on submicron particulate [10-12]. From the meteorological point of view, however, the researchers often get into the meteorological correlation factors of haze, and then analyze the temporal heterogeneity of pollution. Scholars concentrate on the relationship between haze pollution and the changes of atmospheric circulation, as well as the frequency of cold air activity, which further results in changes in near-surface wind speed, temperature, relative humidity, and other meteorological conditions [13-15]. In particular, Zheng deeply analyzed the temporal heterogeneity of pollution in monthly and quarterly units about the special cities and regions such as Beijing and the Yangtze River Delta [16], while Cheng further discussed the possible meteorological prediction tools of haze pollution. [17]. Geographical research focuses on the influence of spatial heterogeneity of special topographic and geomorphological factors $[18,19]$. To sum up, the study of haze pollution in the field 
of natural science has fully demonstrated the spatial heterogeneity of haze itself, and explored the path characteristics of haze pollution to a certain extent.

However, the traditional views like natural determinism and regional transmission reductionism of haze pollution according to natural science research are refuted for the increasingly prominent regional characteristics of haze pollution in China [20]. The relevant studies from the perspective of natural science mainly focus on the formation mechanism of haze, but the theoretical value which analyzes its spatial correlation and heterogeneity, even the theoretical regulatory to policy-making, is limited [21]. As a result, scholars gradually shifted the concentration on haze pollution research to the field of social sciences, and mainly from the perspective of the antecedent and outcome variables of haze pollution caused by the impact of human economic and social development.

From the perspective of antecedent variables, scholars generally initiate their research in pollution intervention policy, and further explore the affecting factors of the issue. Current research is mainly done according to haze pollution of particular key areas or cities, and the variable selection consists of the key directions such as economic production, energy application, and urban development. Among these variables, the economic production includes economic development, industrial structure, foreign trade, technological innovation, chemical production, residue incineration, etc. [22-26]. The core variables of energy application mainly include energy intensity, energy consumption structure, etc. [27-29] and the main variables of urban development include urbanization, vehicle use, and so on [30-33]. The significant relationship between these key variables and haze pollution has been scientifically and rigorously verified in the corresponding studies. The core variables of this study are selected from China's current haze pollution and governance status on a relatively broad time and space span.

For the study on core antecedent variables of haze pollution, the research generally focuses on the exploration of the intervention policy mechanism and treatment means of pollution prevention and control. The significant correlation between spatial partition and haze pollution trajectory indicates that cross-regional cooperation in haze pollution control is of great importance [34]. Zhang further pointed out that it is difficult for government agencies with spatial heterogeneity to initiate cooperation spontaneously, and the introduction of a penalty mechanism will effectively promote stable coordination between government departments on haze control [35]. On the exploration of haze regulation approach, at the enterprise level, government departments should mainly adopt the "long-term supervision" mechanism to promote the comprehensive governance of corporate haze prevention behaviors through measures such as threshold setting of air quality and external environmental atmosphere creation [36]. From the social aspect, based on the changing situations in Beijing from 2011 to 2025, Jia put forward that the current implementation of air pollution in China will effectively achieve the "win-win" result of energy saving, emission reduction, and congestion management by introducing the Air Pollution Charging Fee (APCF) policy [37]. At the same time, Hsiao [38] and other scholars also innovatively proposed cross-domain haze control and mitigation measures such as "Haze Insurance."

From the perspective of outcome variables, the key point is to explore the affecting mechanism of haze pollution from the following two aspects: individual behavior and social economy. For the former, in addition to the obvious factors which seriously affect the physical and mental health of individuals [39], the research of Zhao and Zhang, conducted with data of 31 provinces and municipalities of China in 2013-2015, pointed out that haze pollution has a significant positive impact on residents' purchases of energy-saving electrical appliances and even green consumption behaviors through psychological factors such as internal attitudes, subjective norms, perceived behaviors, personal norms, external government incentives, publicity, and education activities [40,41]. For the latter, haze pollution has a negative effect on low-carbon performance [42]. In the research of the Yangtze River Economic Zone, Dong and Lin argue that haze pollution inhibits industrial agglomeration and industrial production efficiency to some extent, and further has a significant negative impact on regional economic growth by promoting individual depression $[43,44]$. 
From the approach of monitoring and analyzing air pollution distribution, researchers mainly applied such methods as Proximity models, Interpolation models, Land Use Regression models (LURs) and Dispersion models [45-48] in previous studies. Compared to the other ones, the LURs have been more widely used in this field to estimate spatial patterns of air pollutants based on measured values at sampling locations and a set of independent variables $[49,50]$.

Overviewing the previous studies on spatial-temporal heterogeneity of haze pollution, the following gaps can be found. Firstly, according to the characteristics of its affecting path, there is significant spatial-temporal heterogeneity on the impact of economic and social agglomeration and the evolution of science and technology. However, the current research is often carried out from a single perspective, that is to say, the research which focuses on the organic relationship between spatial-temporal heterogeneity is relatively scarce. Secondly, obtainable studies concentrate on the specific areas or pollution incidents, so the mobility of research results and the universality of conclusions are still insufficient. There are also limitations in the selection of data spans, which limits the comparative analysis of the impact path characteristics of haze pollution. At the same time, it should be noted that the existing research mainly focuses on natural sciences. However, with the decreasing proportion of haze pollution affected by natural factors and the increasing demand for its control and management, the transfer of research fields to social science has become a clear trend. At present, in the field of social science, the study on the impact of economic and social development on haze pollution and the intervention methods is still in the initial stage, and presents a series of problems such as limited methods, outdated indicators, and so on.

Therefore, this study aims to fill these gaps on spatial-temporal heterogeneity of haze pollution as follows. Firstly, we comprehensively integrated spatial-temporal heterogeneity factors to explore the characteristics of haze pollution path based on panel data. Secondly, to support spatial and temporal heterogeneity research, this paper selected relevant data of 30 provinces across the country (except Tibet) within 2009 to 2016, which effectively improves the science and universality of the results and conclusions. Thirdly, the economic factors and key detection indicators of haze pollution were placed under the same research framework of the existing research. While comparing and analyzing the complex spatial-temporal heterogeneous effects between variables, the research methods of spatial econometrics were applied to explore the path characteristics of the impact factors of variegated factors on haze pollution, which then provides theoretical and practical reference for constructing a diversified haze pollution control path system.

\section{Research Design}

The spatial-temporal heterogeneity of haze pollution is comprehensively considered by spatial metrology in this study. The method, namely, Exploratory Spatial Data Analysis (ESDA), includes global spatial autocorrelation analysis and local spatial autocorrelation analysis. It is mainly used to explore the non-randomness or autocorrelation of spatial distribution of research objects. In recent years, it has been widely used in many academic fields such as regional economy, regional innovation efficiency, and regional environmental regulation. On the basis of spatial statistical analysis, it is testing the existence of spatial regional correlation and dependence of influencing factors, and, in turn, a spatial econometric model is constructed to explore the characteristics of haze pollution path.

\subsection{Research Methods and Model Construction}

\subsubsection{Spatial Weight Matrix}

In order to demonstrate spatial interdependence, we construct a basic spatial weight matrix $W=\left(W_{i j}\right)_{m \times n}$, which is: 


$$
W=\left[\begin{array}{cccc}
w_{11} & w_{12} & \cdots & w_{1 n} \\
w_{21} & w_{22} & \cdots & w_{2 n} \\
\vdots & \vdots & \vdots & \vdots \\
w_{m 1} & w_{m 2} & \cdots & w_{m n}
\end{array}\right]
$$

Then, the weight matrix is constructed based on spatial adjacency relationship:

$$
W_{i j}=\left\{\begin{array}{c}
1 \text { When region } i \text { and region } j \text { and adjacent } ; \\
0 \text { When region } i \text { and region } j \text { are not adjacent; }
\end{array}\right.
$$

Rook Proximity method is used in this study, where $i=1,2, \cdots, n ; j=1,2, \cdots, m ; m=n$ or $m \neq n$.

\subsubsection{Spatial Autocorrelation}

1. Global spatial autocorrelation analysis. The overall correlation degree of cross-regional observation variables is measured by the global spatial autocorrelation index Moran'I:

$$
\operatorname{Moran}^{\prime} I=\frac{\sum_{i-1}^{n} \sum_{j=1}^{n} W_{i j}\left(X_{i}-\bar{X}\right)\left(X_{j}-\bar{X}\right)}{\sum_{i=1}^{n}\left(X_{i}-\bar{X}\right)^{2} / n} \times \frac{1}{\sum_{i-1}^{n} \sum_{j=1}^{n} W_{i j}}
$$

where $\bar{X}=\frac{\sum_{i=1}^{n} X_{i}}{n}$. The interval of Moran' $I$ is $[-1,1]$, the absolute value represents the strength of correlation, and the signs represent the directional characteristics of spatial correlation.

2. Local spatial autocorrelation. The indicators of Local Indicators of Spatial Association (LISA) are used to reveal the spatial similarity or correlation between different regions, as well as identify the spatial agglomeration and spatial isolation. As a special system of spatial effect, LISA are composed of local Moran'I and local $G_{i}$ and mainly used to test whether local areas tend to agglomerate in space. Therefore, the distribution characteristics of local systems are analyzed by the Moran'I index, Moran scatter plot, and LISA. Meanwhile, the Moran scatter plots are used to describe the correlation between variables $X$ (horizontal axis) and spatial lag vectors $W_{x}$ (vertical axis). High-value areas in the first quadrant are surrounded by high-value areas (high-high); high-value areas in the second quadrant are surrounded by low-value areas (low-high); low-value areas in the third quadrant are surrounded by low-value areas (low-low); low-value areas in the fourth quadrant are surrounded by high-value areas (high-low).

Furthermore, in previous studies, the Moran'I was the most commonly used of LISA. In this study, however, the local Moran'I index is used to measure the degree of agglomeration of region $i$ and region $j$. The degree of agglomeration is calculated in the following equation:

$$
\text { Moran' } I=^{\left(X_{i}-\bar{X}\right)} \frac{\sum_{i=1}^{n}\left(X_{i}-\bar{X}\right)^{2} / n}{n} \sum_{i=1}^{n} W_{i j}\left(X_{i}-\bar{X}\right),(i=1,2, \cdots, n)
$$

Among the formulas, Moran'I positive values are in the form of high-high or low-low, while negative values are in the form of high-low or low-high.

\subsubsection{Spatial Econometric Model}

Two main spatial econometric research and analysis frameworks [31] of spatial lag model (SLM) and spatial error model (SEM) are set up to investigate the impact of diversified key pollution paths factors on haze pollution. 
The SLM model is:

$$
\begin{gathered}
\operatorname{Ln} Y_{i t}=a_{0}+\rho W \operatorname{Ln} Y_{i t}+a_{1} \operatorname{LnGDP_{it}}+a_{2} S T R U_{i t}+a_{3} \operatorname{LnINO}_{i t}+a_{4} E N E_{i t}+a_{5} U R B_{i t} \\
+a_{6} C A R_{i t}+\varepsilon_{i t}, \varepsilon_{i t} \sim N\left(0, \sigma_{i t}^{2}\right)
\end{gathered}
$$

where $Y_{i t}$ refers to the haze pollution situation in the $t$ year of the i region; $\mathrm{w}$ refers to the spatial weight matrix; $W \operatorname{Ln} Y_{i t}$ refers to the spatial lag variable of innovation performance in adjacent regions; $\rho$ is a spatial autocorrelation regression coefficient, indicating the spatial spillover effect of haze pollution level in adjacent regions on the pollution in the region; Economic growth (GDP), Industrial structure (STRU), Innovation performance (INO), Energy intensity (ENE), Urbanization level (URB) and Traffic pollution (CAR) respectively refer to the 6 key variables, which all have a real impact on the path of haze pollution in the region. The symbol a refers to coefficients of the corresponding variables and $\varepsilon$ is random error vector.

Correspondingly, the SEM model affecting haze pollution level was constructed as below:

$$
\begin{gathered}
\operatorname{Ln} Y_{i t}=a_{0}+a_{1} L n G D P_{i t}+a_{2} S T R U_{i t}+a_{3} \operatorname{LnINO}_{i t}+a_{4} E N E_{i t}+a_{5} U R B_{i t}+a_{6} C A R_{i t} \\
+\varepsilon_{i t}, \varepsilon_{i t}=\lambda W \varepsilon_{i t}+\mu_{i t}, \mu_{i t} \sim N\left(0, \sigma_{i t}^{2}\right)
\end{gathered}
$$

where $\lambda$ refers to the spatial error coefficient, which indicates the impact of haze pollution level in adjacent regions on haze pollution in this region. $\mu$ refers to the random error vector.

\subsection{Indicators and Data}

This study summarizes and refines the relevant research conclusions of the existing literature. On the basis of the established haze pollution degree as a dependent variable, the independent variables of impacting factors are integrated into 3 core modules: economic production, energy application, and urban development. Among them, economic production module mainly includes economic growth, industrial structure, and innovation performance; energy application is mainly represented by energy intensity; and urban development refers to the level of urbanization, traffic pollution, and other indicators.

Haze pollution ( $\mathrm{Y}$ ) $\mathrm{PM}_{2.5}$ and $\mathrm{PM}_{10}$ are widely recognized as key components and measurement indicators of haze [51]. Existing literatures are concerned with the methods of assessing haze pollution level via these two indicators. However, $\mathrm{PM}_{2.5}$ was not included in China's monitoring indicators until the "Ambient Air Quality Standard" was revised in 2012. In addition to the limitation of the coverage of the "Three-step" Data Publication Plan proposed by the Ministry of Environmental Protection, the $\mathrm{PM}_{2.5}$ data of the Chinese meteorological monitoring system is relatively lagging behind. In contrast, early in September 1996, $\mathrm{PM}_{10}$ was listed as a key monitoring item in the "Hygienic Standard for Public Places" in China. Considering statistical and economic significance, this study selected $\mathrm{PM}_{10}$ to measure the level of haze pollution in different regions.

The key interprovincial heterogeneity characteristics of haze pollution in 2009-2016 of China at spatial level are shown in Figure 1, where the average annual concentration of $\mathrm{PM}_{10}$ indicated by the longitudinal dashed line is $101.44 \mu \mathrm{g} / \mathrm{m}^{3}$, which is generally higher than $70 \mu \mathrm{g} / \mathrm{m}^{3}$ of the average annual level of level II, which is stipulated in the "Ambient Air Quality Standard" (GB3095-2012) implemented by China on 1 January 2016. Among the provinces with above-average concentration, the eastern, central and western regions accounted for $50 \%, 44.44 \%$, and $66.67 \%$, respectively. The overall distribution was relatively balanced, and coincided with the current economic development strategy of the Western Development.

Economic growth (GDP). The level of economic development is closely related to environmental quality. In the beginning stage of rapid economic growth, environmental damage is aggravated. After a period of such development, the environment issue arouses wide concern, which calls for a balance between economic development and environmental protection. Therefore, effective regulation of environmental pollution would be enabled. Such a model of sustainable low-carbon economy 
contributes to effective regulation of environmental pollution [52]. We use a regional GDP index to show economic growth, and use price index deflation to eliminate the impact of price changes.

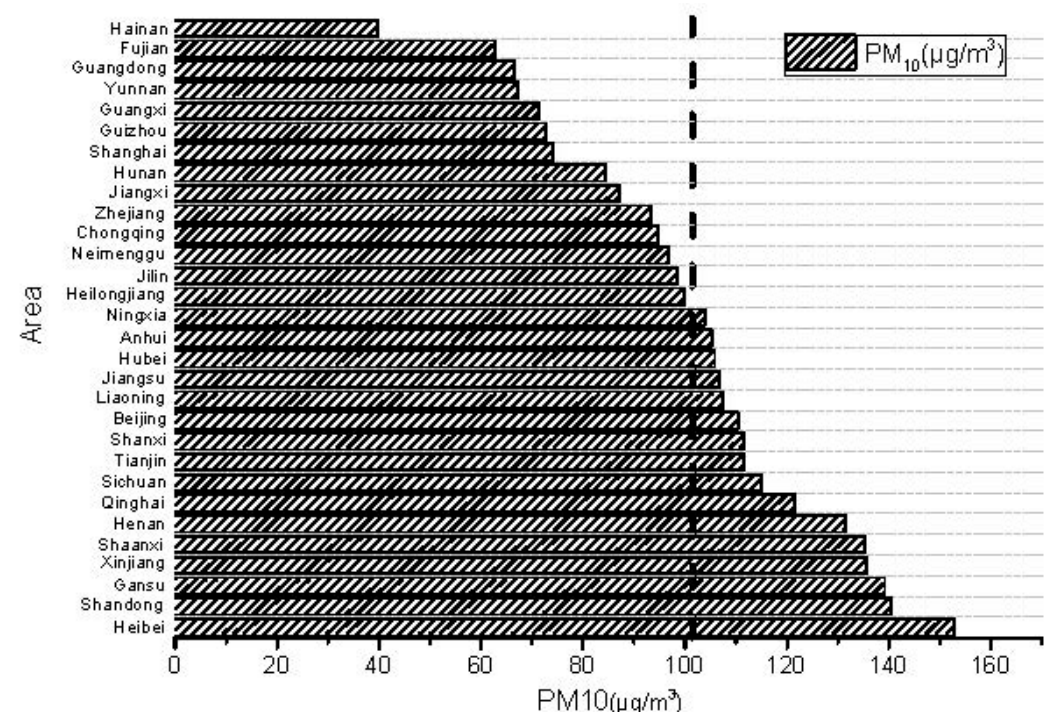

Figure 1. Spatial Heterogeneous Distribution of Haze Pollution.

Industrial structure (STRU). Unbalanced industrial structure dominated by secondary industry has always been considered as one of the main sources of environmental impact in the process of economic development. It has been used as the key indicator of pollution level in existing studies $[21,53]$. In this study, the share of added value from secondary industry in regional economic growth is used to represent the industrial structure, which eliminates the differences in data composition caused by the inconsistency of regional economic development level. Thus, it effectively improves the comparability of industrial structure data across regions.

Innovation performance (INO). Technological innovation provides an important method for haze pollution control, which significantly affects its degree in the region. In addition, some studies have pointed out that average number of patent applications per year is a comprehensive index to measure the degree of regional technological innovation activities and the level of scientific research output [54]. Based on the characteristics of regional data, this study uses the annual number of regional patent authorizations to measure the innovation performance level of each province.

Energy intensity (ENE). This refers to the energy intensity which fully reflects the development level of energy-saving and emission-reduction technology [52]. We use energy consumption per unit GDP as an indicator of energy intensity; the smaller the index, the lower the energy resource consumption under the given output. This shows that the more advanced the production technology gets, the higher the energy efficiency [55].

Urbanization level (URB). The issue of urban population agglomeration caused by the continuous improvement of urbanization level has a significant positive impact on haze pollution [31]. This study measures the level of regional urbanization through the proportion of urban population The proportion of urban population is calculated according to the ratio of urban population to total population in each province/city.

Traffic pollution (CAR). Singh and Huang have pointed out that vehicle exhaust is a key component of haze pollution $[34,56]$. In this study, the per capita ownership of civil vehicles was used to measure the regional traffic pollution level. This variable adequately measures the impact of vehicle emissions on haze pollution, and, at the same time, the per capita level partially circumvents the difference caused by the inconsistent level of development between regions.

In this study, the provincial panel data of haze pollution and related factors in 30 provinces/municipal cities (Except Tibet) of China from 2009 to 2016 were used. The main sources of 
data are "China Statistical Yearbook on Environment," "China Energy Statistical Yearbook," "China Statistical Yearbook," provincial statistical yearbooks and the Statistical Communique of the People's Republic of China on the National Economic and Social Development. Due to the consideration of eliminating the impact of price changes, economic growth indicators are deflated by using the GDP deflator index, and the data are from 2009. The descriptive statistical results of sample data are shown in Table 1 below.

Table 1. Sample descriptive statistics.

\begin{tabular}{cccccc}
\hline Variable & Mean Value & Standard Deviation & Minimum Value & Maximum Value & Sample Size \\
\hline Y & 101.4375 & 32.8792 & 30 & 305 & 240 \\
GDP & 9.458897 & 0.8778152 & 6.985891 & 11.1806 & 240 \\
STR & 0.4653963 & 0.0814997 & 0.192622 & 0.590454 & 240 \\
INO & 9.569058 & 1.494218 & 5.575949 & 12.50597 & 240 \\
ENE & 0.9683548 & 0.5347534 & 0.2835 & 3.45 & 240 \\
URB & 54.76021 & 13.09387 & 29.89 & 89.6 & 240 \\
CAR & 0.0920264 & 0.0474182 & 0.024161 & 0.251928 & 240 \\
\hline
\end{tabular}

\section{Haze Pollution Path, Spatio-Temporal Heterogeneity and Structural Distribution}

Considering the spatial-temporal heterogeneity of haze pollution, this part explores the path characteristics of haze pollution in China from the two dimensions of time and space. The development characteristics of the core path of haze pollution in China are studied relating to the economic and social reality in the east, centre and west of China. Meanwhile, a further exploring of the spatial pattern and structure of haze pollution in China is carried out from the perspective of spatial research.

\subsection{Time Trends Development Characteristics of Haze Pollution}

Shown in Figure 2 are the path development characteristics of the haze-pollution time, the level of national average, as well as the level of the eastern, central and western regions. From the overall development path of haze pollution level, the two periods of 2009-2012 and 2013-2016 show a stable and slightly declining trend. However, it is noteworthy that the average $\mathrm{PM}_{10}$ within 2012-2013 increased sharply from $92.33 \mu \mathrm{g} / \mathrm{m}^{3}$ to $128.5 \mu \mathrm{g} / \mathrm{m}^{3}$, and although a downward trend showed in the following years, it did not fall below the monitored data in 2009 until 2016. The main reason is that, in the autumn and winter of 2011, under the influence of a wide range of persistent severe haze weather throughout the country, China issued the Ambient Air Quality Standard (AQS) in 2012. The new standard incorporated $\mathrm{PM}_{2.5}$ into the monitoring indicators, and stipulated that cities must report their air monitoring data in hours and publish them in real time [57], which further promoted the standardization of air quality monitoring and made the quality of monitoring data significantly improved, thus leading to a considerable fluctuation in the national $\mathrm{PM}_{10}$ data in 2013. Although haze pollution control has achieved considerable success in recent years, and the downward trend of pollution concentration is significant, the overall $\mathrm{PM}_{10}$ level in China is still higher than the annual average secondary level stipulated in the new standard, i.e., there is still much room for improvement.

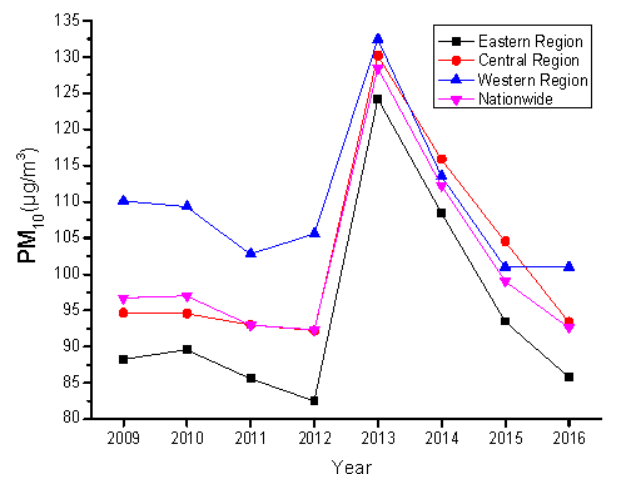

Figure 2. Development characteristics of time trends about haze pollution in China. 
Considering the spatial characteristics of the eastern, central, and western regions of China, the overall trend is consistent with the national path evolution characteristics. Specifically, the level of $\mathrm{PM}_{10}$ in eastern China is lower than that in central and western regions every year, and the downward trend is significant. Moreover, the pollution issue is particularly prominent in the western region, and the haze control effect represented by the decrease of $\mathrm{PM}_{10}$ within the years from 2015 to 2016 has gradually slowed down and even disappeared. This phenomenon echoes the existing research of $\mathrm{Hu}$ [58], which fully reflects the developmental characteristics of the path of China's polluting industries gradually gathered from the east to the central and western regions at the time level.

It can be seen in Figure 2, since 2013, as our efforts in air pollution control have been continuously increased, testing standards and governance methods have made considerable progress, and the problem of haze pollution has been tangibly mitigated. However, it is noteworthy that, on the one hand, the current $\mathrm{PM}_{10}$ index is still far from meeting the corresponding standards stipulated in the regulations, and there is still a long way to go to abate or even eliminate haze pollution; on the other hand, the pollution problem gradually changes in space with the focus of economic development, and shifts from the east to the central and western regions. At present, the problem of pollution in western China has become relatively prominent, and the effect of pollution control is relatively weak, which has aroused more attention.

\subsection{Spatial Correlation and Pattern of Haze Pollution}

In this study, the Geo DA 9.5 was used to measure global Moran's I and analyze the spatial correlation of haze pollution. Furthermore, Moran scatter and LISA agglomeration are used to further display the local spatial correlation, difference degree, spatial pattern of each region and its surrounding areas.

The results of Moran index calculation are shown in Table 2. Moran index values of haze pollution in 2009-2016 are all greater than 0 and significant at $1 \%$ level, which shows a positive spatial autocorrelation. Meanwhile, with the change of time, the Moran index shows a certain growth trend, which exhibits that the haze pollution in China tends to agglomerate in space, i.e., the spatial autocorrelation effect gradually increases.

Table 2. Global autocorrelation Moran's I index of haze pollution for 2009-2016 in China.

\begin{tabular}{ccc}
\hline Years & Moran's I & $\boldsymbol{P}$ \\
\hline 2009 & 0.4181 & 0.001 \\
2010 & 0.3525 & 0.002 \\
2011 & 0.3345 & 0.001 \\
2012 & 0.3237 & 0.002 \\
2013 & 0.3476 & 0.001 \\
2014 & 0.4971 & 0.001 \\
2015 & 0.5060 & 0.001 \\
2016 & 0.5232 & 0.001 \\
\hline
\end{tabular}

To show the spatial distribution of haze pollution in China, Moran scatter plots of haze pollution in 2009-2016 are drawn as shown in Figures 3-6 below. According to the images, the data of most areas mainly fall into the first and third quadrants, and the first quadrant is slightly prominent. This further demonstrates that haze pollution has significant external and spillover effect. That is to say, the distribution of haze pollution in each Chinese province and city has a significant positive correlation in space, and haze pollution of two adjacent regions affects each other. 


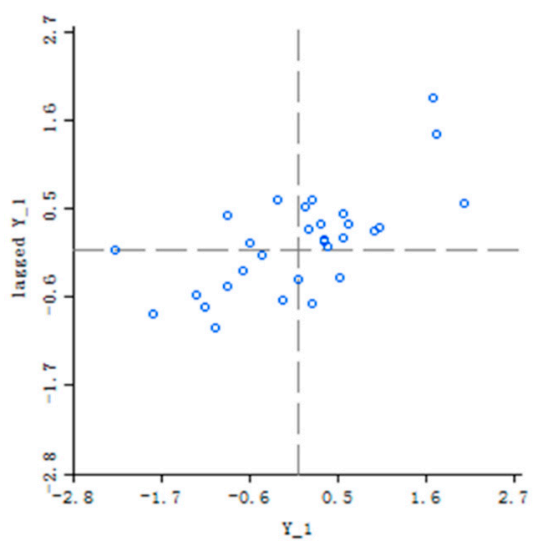

(3-1)

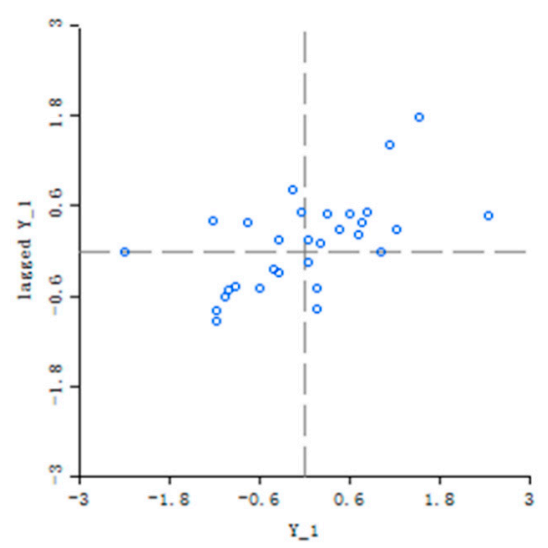

(3-2)

Figure 3. Moran scatter plot of haze pollution in China (2009 (3-1), 2010 (3-2)).

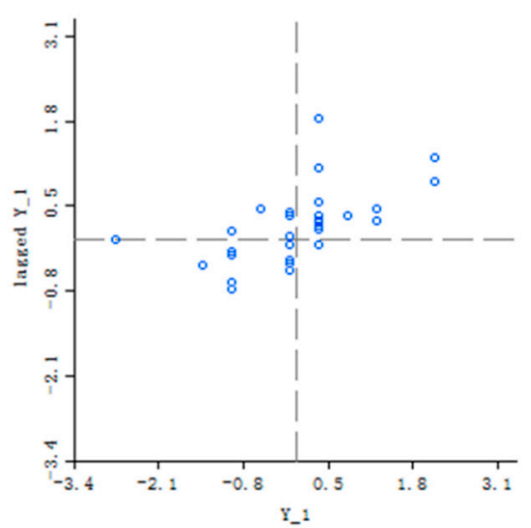

(4-1)

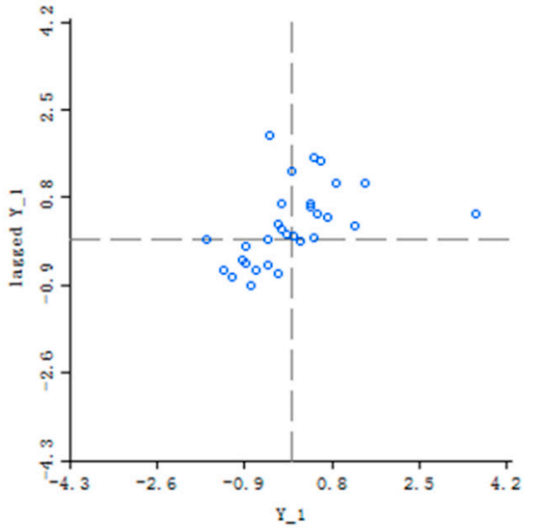

(4-2)

Figure 4. Moran scatter plot of haze pollution in China (2012 (4-1), 2013 (4-2)).

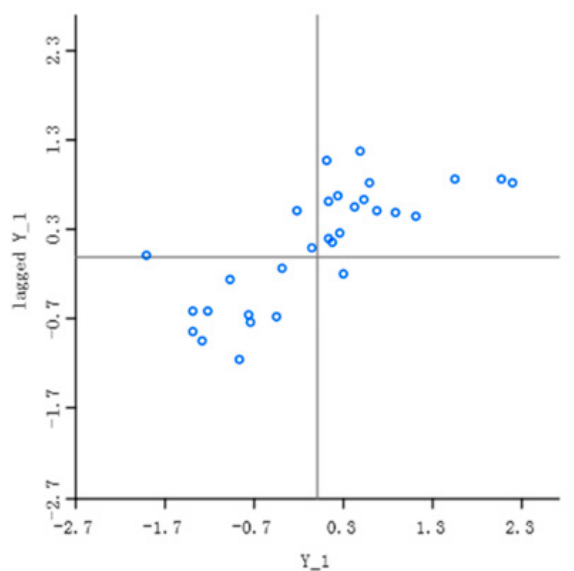

(5-1)

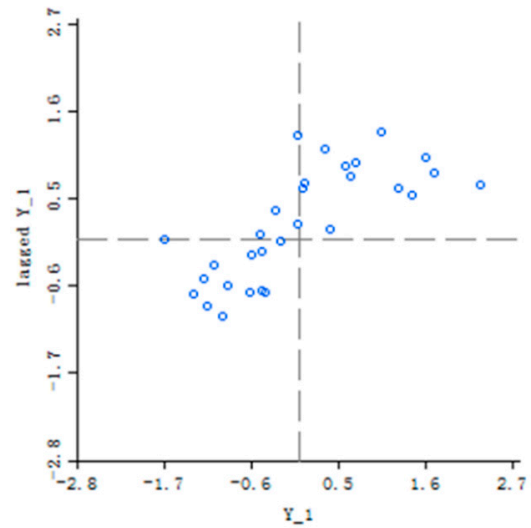

(5-2)

Figure 5. Moran scatter plot of haze pollution in China (2015 (5-1), 2016 (5-2)). 


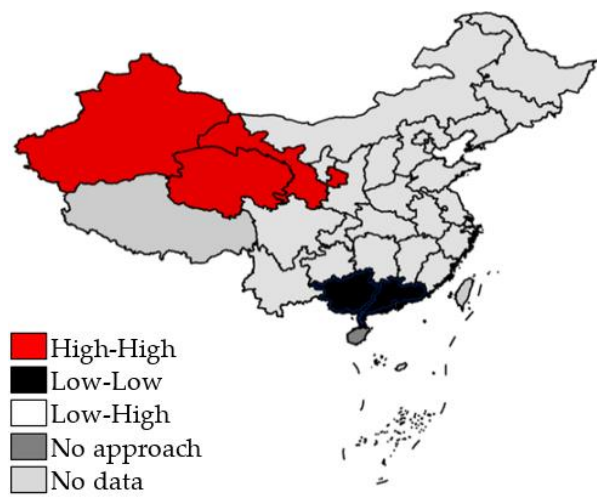

6-1

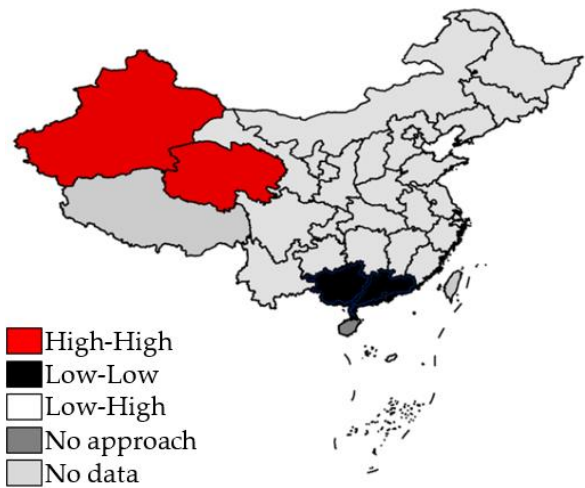

$6-2$

Figure 6. LISA agglomeration map of haze pollution in China (2009 (6-1), 2010 (6-2)).

Note: Due to the limitation of space, we choose the comparative representation analysis of the main representative years, the same as the following.

On the basis of the above results, this study further tests the spatial correlation of local areas by LISA aggregation map, as shown in Figures 6-8. Haze pollution has formed different aggregation areas because of the spatial distribution characteristics. Except that Hainan Province has been in a state of "no approach" for a long time, the high-value agglomeration areas mainly appear in the central and western regions within 2009-2012, while the path development trend from 2013 to 2016 prevails in the eastern regions and gradually transfers to the central and western regions of China. The main reason for this change is the strictness and refinement of the Chinese air quality monitoring system; secondly, the low-value areas mainly gather in the central and eastern coastal areas, remaining relatively stable; at the same time, from a spatial point of view, the low-value areas show a significant development trend towards central and eastern China. Coastal areas show relatively good meteorological diffusion conditions, and the regulation degree there is relatively strict. Given the above path development characteristics, it is not difficult to find that the haze pollution mainly presents high-high and low-low states in space. On the one hand, the high degree of pollution has significant spatial correlation, which indicates that the haze itself has a strong diffusive influence [20]; on the other hand, it should be noted that the low degree of pollution often has a weak connection with the surrounding areas, and the provinces with great haze control have insufficient driving effect on the neighboring areas.

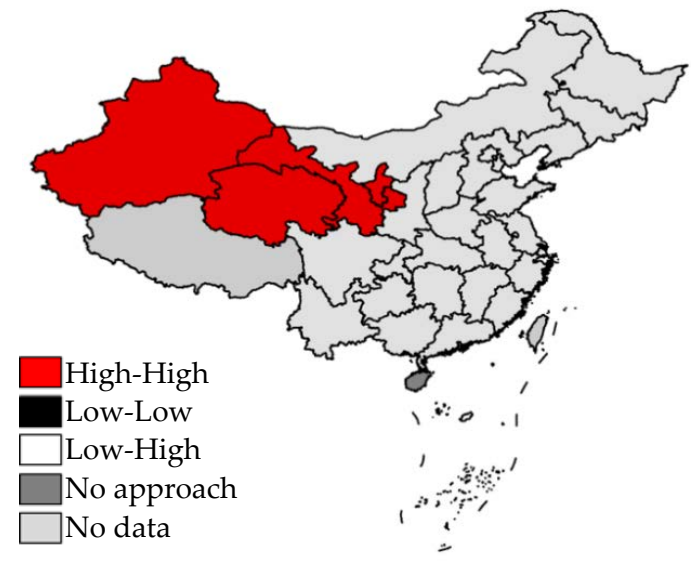

(7-1)

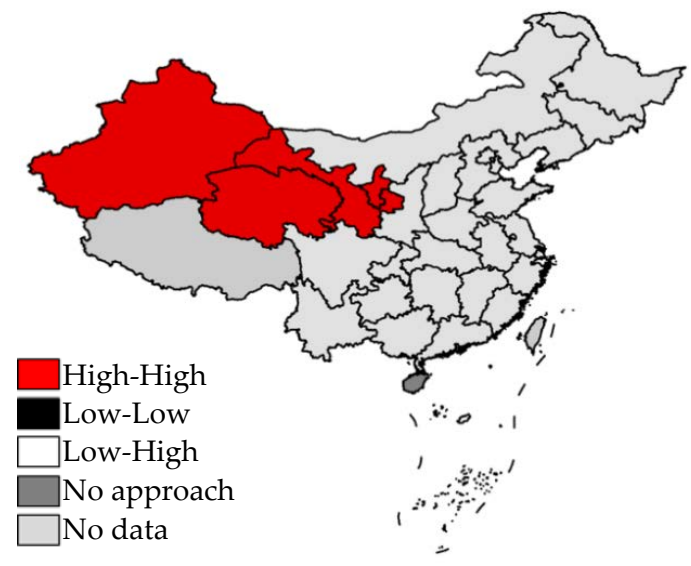

(7-2)

Figure 7. LISA agglomeration map of haze pollution in China (2012 (7-1), 2013 (7-2)). 


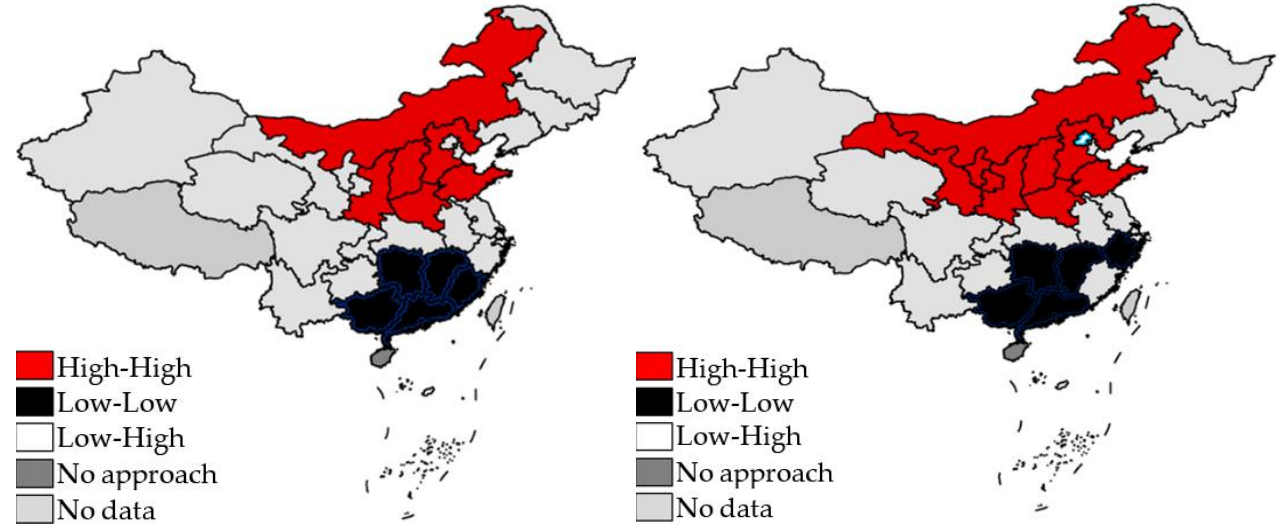

8-1

$8-2$

Figure 8. LISA agglomeration map of haze pollution in China (2015 (8-1), 2016 (8-2)).

\section{Spatial Econometric Analysis of the Effects of Diversified Factors on Haze Pollution Path Characteristics}

The analysis of spatial-temporal characteristics of haze pollution clearly points out its significant complexity and difference in time and spatial distribution, which makes diversified factors play a key role in the formation of haze pollution and has significant spatial and temporal heterogeneity. For the purpose of exploring feasible suggestions for haze control, this study focuses on the factors that can be intervened to improve the situation, and a spatial econometric model of the impact of diversified core factors on haze pollution is constructed, and, further, the analysis about the haze pollution path characteristics from a spatial perspective is carried out.

First, the LM test is used to select the model. SLM and SEM were screened by the significance of LM-LAG, Robust LM-LAG, LM-ERR and Robust LM-ERR statistics. Table 3 shows that the LM values of the above four models are significant at $1 \%$ level. Compared with LM-ERR, LM-LAG is more significant, whereas both Robust LM-LAG and Robust LM-ERR are not significant, so the spatial lag model (SLM) is more suitable. The Hausman test-statistic equals $19.22(P=0.0034<0.05)$, which rejects the null hypothesis of random effect, so the fixed-effect model should be adopted.

Table 3. Model Selection Test.

\begin{tabular}{ccc}
\hline Variable & Statistic & $p$ Value \\
\hline Moran'I & 1.699 & 0.0450 \\
LM_spatial_lag & $66.936^{* * *}$ & 0.000 \\
Robust_LM_spatial_lag & 1.141 & 0.285 \\
LM_spatial_err & $70.015^{* *}$ & 0.000 \\
Robust_LM_spatial_err & $4.220^{* *}$ & 0.040 \\
\hline \multicolumn{2}{c}{ Note: ${ }^{* * *} p<0.01 ;{ }^{* *} p<0.05 ; * p<0.1}$.
\end{tabular}

Furthermore, based on the characteristics of data, a comprehensive SLM fixed-effect model, including unfixed-effect model, time-fixed effect model, space-fixed effect model and space-time-fixed effect model, is applied to conduct analysis. As shown in Table 4, SLM time-fixed-effect model has a high statistical fitness and relatively strong explanatory power. 
Table 4. Spatial econometric test results of the effects of diversified key factors on haze pollution in China.

\begin{tabular}{|c|c|c|c|c|c|c|c|c|}
\hline \multirow{2}{*}{ Variable } & \multicolumn{4}{|c|}{ SLM } & \multicolumn{4}{|c|}{ SEM } \\
\hline & $\begin{array}{c}\text { Unfixed } \\
\text { Effect Model }\end{array}$ & $\begin{array}{l}\text { Fixed-Time } \\
\text { Effect Model }\end{array}$ & $\begin{array}{l}\text { Space Fixation } \\
\text { Effect Model }\end{array}$ & $\begin{array}{l}\text { Space-Time Fixation } \\
\text { Effect Model }\end{array}$ & $\begin{array}{c}\text { Unfixed } \\
\text { Effect Model }\end{array}$ & $\begin{array}{l}\text { Fixed-Time } \\
\text { Effect Model }\end{array}$ & $\begin{array}{l}\text { Space Fixation } \\
\text { Effect Model }\end{array}$ & $\begin{array}{l}\text { Space-Time Fixation } \\
\text { Effect Model }\end{array}$ \\
\hline GDP & $\begin{array}{l}0.045 \\
(0.50)\end{array}$ & $\begin{array}{l}0.049 \\
(0.93)\end{array}$ & $\begin{array}{c}-0.529^{* *} \\
(-2.27)\end{array}$ & $\begin{array}{c}-0.742 * \\
(-1.75)\end{array}$ & $\begin{array}{l}0.032 \\
(0.35)\end{array}$ & $\begin{array}{l}0.059 \\
(1.10)\end{array}$ & $\begin{array}{c}-0.537^{* *} \\
(-1.96)\end{array}$ & $\begin{array}{c}-0.724^{*} \\
(-1.71)\end{array}$ \\
\hline STR & $\begin{array}{c}0.932 * * * \\
(2.62)\end{array}$ & $\begin{array}{c}1.110^{* * *} \\
(4.20)\end{array}$ & $\begin{array}{l}0.512 \\
(1.23)\end{array}$ & $\begin{array}{l}0.187 \\
(0.34)\end{array}$ & $\begin{array}{l}0.909 * * \\
(2.33)\end{array}$ & $\begin{array}{c}1.169 * * * \\
(4.27)\end{array}$ & $\begin{array}{l}0.357 \\
(0.73)\end{array}$ & $\begin{array}{l}0.204 \\
(0.37)\end{array}$ \\
\hline INO & $\begin{array}{l}-0.028 \\
(-0.58)\end{array}$ & $\begin{array}{l}0.013 \\
(0.40)\end{array}$ & $\begin{array}{l}0.012 \\
(0.19)\end{array}$ & $\begin{array}{l}0.012 \\
(0.18)\end{array}$ & $\begin{array}{l}0.001 \\
(0.01)\end{array}$ & $\begin{array}{l}0.008 \\
(0.24)\end{array}$ & $\begin{array}{l}0.031 \\
(0.47)\end{array}$ & $\begin{array}{l}0.015 \\
(0.22)\end{array}$ \\
\hline ENE & $\begin{array}{l}0.073 \\
(1.21)\end{array}$ & $\begin{array}{c}0.143^{* * *} \\
(2.64)\end{array}$ & $\begin{array}{l}-0.024 \\
(-0.34)\end{array}$ & $\begin{array}{l}-0.014 \\
(-0.18)\end{array}$ & $\begin{array}{l}0.068 \\
(1.05)\end{array}$ & $\begin{array}{c}0.144^{* * *} \\
(2.65)\end{array}$ & $\begin{array}{l}0.021 \\
(0.28)\end{array}$ & $\begin{array}{l}-0.009 \\
(-0.12)\end{array}$ \\
\hline URB & $\begin{array}{l}-0.005 \\
(-1.47)\end{array}$ & $\begin{array}{c}-0.009 * * * \\
(-4.17)\end{array}$ & $\begin{array}{l}0.012 \\
(1.20)\end{array}$ & $\begin{array}{l}0.017 \\
(1.55)\end{array}$ & $\begin{array}{c}-0.008 * \\
(-1.91)\end{array}$ & $\begin{array}{c}-0.009 * * * \\
(-4.06)\end{array}$ & $\begin{array}{l}0.013 \\
(1.26)\end{array}$ & $\begin{array}{l}0.016 \\
(1.50)\end{array}$ \\
\hline CAR & $\begin{array}{c}2.471^{* * *} \\
(3.64)\end{array}$ & $\begin{array}{c}4.045^{* * *} \\
(6.34)\end{array}$ & $\begin{array}{c}3.155^{* * *} \\
(2.68)\end{array}$ & $\begin{array}{l}3.401 * * \\
(2.53)\end{array}$ & $\begin{array}{c}3.669 * * * \\
(3.94)\end{array}$ & $\begin{array}{c}4.031^{* * *} \\
(6.29)\end{array}$ & $\begin{array}{c}3.492 * * * \\
(2.91)\end{array}$ & $\begin{array}{l}3.387 * * \\
(2.52)\end{array}$ \\
\hline$\rho / \lambda$ & $\begin{array}{c}0.750 * * * \\
(11.77)\end{array}$ & $\begin{array}{l}0.118 \\
(0.52)\end{array}$ & $\begin{array}{l}0.788^{* *} \\
(13.94)\end{array}$ & $\begin{array}{l}0.238 \\
(1.14)\end{array}$ & $\begin{array}{l}0.776^{* * *} \\
(12.99)\end{array}$ & $\begin{array}{l}-0.162 \\
(-0.54)\end{array}$ & $\begin{array}{l}0.786^{* * *} \\
(14.14)\end{array}$ & $\begin{array}{l}0.199 \\
(0.88)\end{array}$ \\
\hline $\mathrm{R}^{2}$ & 0.229 & 0.259 & 0.006 & 0.009 & 0.247 & 0.261 & 0.003 & 0.008 \\
\hline Log Likelihood & 41.860 & -12.736 & 101.004 & 111.2679 & 44.604 & -12.708 & 101.611 & 111.028 \\
\hline $\mathrm{N}$ & 240 & 240 & 240 & 240 & 240 & 240 & 240 & 240 \\
\hline
\end{tabular}


Specifically, the regression coefficients of industrial structure (STR), energy intensity (ENE), urbanization level (URB) and traffic pollution (CAR) to haze pollution in the model are 1.11, 0.143, -0.009 , and 4.045 , respectively, which are all significant at $1 \%$ level. In contrast, the regression coefficients of Economic growth (GDP) and innovation performance (INO) were 0.049 and 0.013 , respectively, but they were not significant. This shows that STR, ENE, and CAR have played a role in deteriorating the haze pollution problem, while the development of URB has produced a small amount of curb. In contrast, GDP and INO have a weak role to make the haze pollution worsen, but they have not been fully developed. GDP and INO have less impact on haze pollution, yet they are still on the way for further development. In view of the data results, we argue that STR and ENE, as objective and comprehensive indicators, have an obvious positive impact on haze pollution. In addition, the impacting factors are closely related to the stage of socioeconomic development. In the early stage of rapid economic construction, GDP, INO, and other factors are likely to have a strong negative impact on it. However, with the further advancement of the Chinese economy and technology, the national productivity has been effectively improved, and the protection of ecological environment has gradually drawn attention from the government and the public. On the one hand, in order to avoid the problem of "Treatment after Pollution," the government will adopt a series of measures to coordinate the relationship between economic, innovative development and environmental protection [59], so as to weaken the negative relationship between GDP and haze pollution, and even produce a positive regulatory effect. At present, the corresponding trend of the Chinese GDP has emerged initially. However, due to the insufficient level of innovation and the low rate of actual conversion and utilization of innovative technology, the intervention effect of INO promotion on haze pollution has not been highlighted. On the other hand, improvement of the living standards has led to a sharp increase in the number of private cars; CAR has become increasingly prominent. At the same time, according to the model, the URB coefficient is negative and significant, that is to say, the continuous improvement of URB leads to the decrease of haze pollution. This result is consistent with the research of Wang: In the stage of low-degree urbanization, urban development leads to the aggravation of pollution; however, the pollution emission will gradually decrease when it develops to a certain extent [60]. According to the results, this study further proposes that the public's demand for livable environment continues to increase with the social development. High-degree urbanization promotes relatively strict environmental control and enhances livability of the environment; for the purpose of attracting foreign investment, expanding production and promoting economy, low-degree urbanization areas tend to have a low level of environmental regulation, which leads to relatively serious haze pollution problem.

Secondly, it should be noted that the spatial lag coefficient of the SLM model is $\rho / \lambda=0.118$, which is not significant. This result shows that spatial factors have little effect on haze pollution, which is consistent with the existing research result, that is to say, the spatial heterogeneity of haze pollution is often based on natural science variables, while the social science factors often impact the evolution of haze in the form of temporal heterogeneity through a certain stage of development [61].

\section{Conclusions and Enlightenment}

The study of haze in this paper is mainly based on the economic perspective, and focuses on the paradigm of social science, which is an independent research paradigm, and there are certain differences with the atmospheric chemistry of atmospheric dynamics processes on research ideas. At the same time, according to relevant literatures, we fully ensured that, under the research framework of social science, the results and the recommendations are reasonable and reliable. Based on this, we have drawn the following conclusions and enlightenment.

\subsection{Research Conclusions}

From the perspective of economic and social development, it is a complex task to explore the path characteristics and influencing factors of haze pollution under the evolution of spatial-temporal heterogeneity. In this study, we systematically measured the path development characteristics of haze 
pollution in China in terms of time and space by spatial econometrics, and brought spatial factors into the framework of multiple influencing factors mechanisms to analyze the mechanism of haze pollution. The analysis of the characteristics and influencing factors of haze pollution under spatial-temporal heterogeneity provides a stronger basis for the long-term control of haze pollution, as concluded below.

The time trends of haze pollution in China show a significant overall declining trend, with partial migration from the eastern to the western regions. Specifically, since the implementation of the Ambient Air Quality Standard in 2013, haze pollution has been abating year by year, but the intensity is gradually slowing down. Considering the regional division of the middle, east, and west of China, with the change in economic development mode and environmental governance mechanism, the main traditionally polluted towns in the eastern regions are transferring to the mid-west, to which due attention should be paid.

For the spatial correlation and pattern of haze pollution in China, the pollution agglomeration is prominently lacking in effective spillover of regulation. On the one hand, pollution distribution in China has a significant spatial spillover effect, namely, the haze problem has clear characteristics of spatial agglomeration, and high-polluted provinces have serious negative externality to the surrounding areas; on the other hand, the effective environmental regulation lacks the correlation in space, that is, great regional pollution control measures fail to have a driving effect on the surrounding provinces and cities.

Factors such as Industrial STR, ENE and CAR have a significant positive impact on haze pollution, whereas URB has a significant negative impact. However, GDP and INO have no significant positive impact on haze pollution, namely, their driving effect is weak. Specifically, although STR and ENE have a significant positive impact on haze pollution, the broader mechanism of economic and social indicators is closely related to the level of national development, and shows heterogeneous phase characteristics. Because the economic production mode in China still needs to be further upgraded, and innovation capability is insufficient, technology transformation and utilization rate is low. Consequently, both the GDP and INO still have a weak push for haze pollution rather than intervention. With the development of society, people's pursuit of living standards and livable environment continues to increase. First of all, CAR as the representative of the factors closely related to daily life has been prominent towards the impact on haze pollution. Secondly, the pursuit of livable environment has promoted the population agglomeration factor represented by the high URB to effectively push forward the rapid development of haze pollution control, and also promoted the efficient implementation of regional environmental regulation.

\subsection{Enlightenment and Suggestions}

The spatial-temporal heterogeneous path characteristics of haze pollution are the key to the analysis of this study. The following is provided as a practical and theoretical reference for further planning and means selection of environmental regulation policy.

Based on the path of time evolution, in reality, the urgent task at this stage in China is noticing the situation that air pollution control efforts are gradually weakened, especially in areas with severe pollution. Combined with the important deployment of the "Three-year Action Plan for Winning the Blue Sky Defence War" in China, a comprehensive process monitoring feedback mechanism is established through the implementation of regulatory and standard policies with strict implementation of accountability, to promote the pollution problem into a rapid improvement period again. Secondly, on the basis of the implementation link, we need to pay attention to adjust the layout of pollution control in the medium and long term, and put forward the importance of pollution control in the central and western regions of China. Finally, according to long-term sustainable development, further pollution control strategies such as promoting the rapid development of clean energy and green production technology should be implemented, and a new round of vitality into the haze regulation should be injected, especially in the heavy industrial agglomeration areas, such as the central and western regions. In the long run, we should combine the optimization of industrial and energy 
consumption structure with flexible adjustment of regulatory policies [62]. On the one hand, we should improve energy efficiency by technology upgrading; on the other hand, the government in China should face the urgency of the economic development situation in the central and western regions and gradually improve environmental regulatory standards to continuously promote the comprehensive improvement of the haze pollution problem.

China should construct an interregional cooperation and responsibility-sharing mechanism for pollution control from an administrative perspective, by the low spillover effect of the governance on haze pollution in spatial dimension. Because of the significant heterogeneity in objective factors, it is difficult for regional governments to spontaneously form a relatively stable cooperation model [35]; consequently, regions with good pollution regulation measures have not produced a real driving effect on the surrounding areas. Therefore, in the process of implementing the haze pollution regulations in an administrative perspective, China should, through legislation and accountability, effectively guide interregional pollution control cooperation, and enhance the driving role of high-level governance areas to the surrounding areas. For example, an efficient platform for communication and experience should be built and shared to promote the effective exchange and reference of governance measures; at the same time, we should introduce a scientific reward and punishment mechanism, strengthen the sense of responsibility so as to comprehensively promote the continuous and effective improvement of joint regulatory efficiency.

The intervention of economic, technological, and social development on haze pollution needs to be enhanced to full play. Firstly, the government should optimize the industrial structure, promote the benign development of the economy, and then play a supporting role in the regulation of haze pollution from the economic basis; secondly, we should promote innovation drive and technology transformation, so as to optimize the production mode, and promote pollution governance by production means upgrading; thirdly, the local government should comprehensively improve the level of living environment, and strengthen the fundamental driving effect of social development needs on the regulation of haze pollution, then force the continuous improvement and efficient implementation of the pollution governance system through the rapid improvement of urbanization level.

Author Contributions: J.H. conceived and designed the experiments; J.H. performed the experiments; J.H. and S.Z. analyzed the data; H.S. and F.L. contributed reagents/materials/analysis tools; J.H. and S.Z. wrote the paper.

Funding: This research was funded by the Fundamental Research Funds for the Central Universities, grant number [2019RW20] and China Postdoctoral Science Foundation, grant number [2019M650519].

Acknowledgments: We are indebted to the anonymous reviewers, editor and native language polish team of Duan.

Conflicts of Interest: The authors declare no conflict of interest. The founding sponsors had no role in the design of the study; in the collection, analyses, or interpretation of data; in the writing of the manuscript, and in the decision to publish the results.

\section{References}

1. Chen, L.L.; Zhang, X.D.; He, F.; Yuan, R.S. Regional green development level and its spatial relationship under the constraints of haze in China. J. Clean. Prod. 2019, 210, 376-387. [CrossRef]

2. Liu, H.M.; Fang, C.L.; Huang, J.J.; Zhu, X.D.; Zhou, Y.; Wang, Z.B.; Zhang, T. Spatio-temporal characteristics and influencing factors of air pollution in Beijing-Tianjin-Hebei urban agglomeration. Acta Geogr. Sin. 2018, 73, 177-191.

3. Leeuw, F.A.M.D.; Moussiopoulos, N.; Sahm, P.; Bartonova, A. Urban air quality in larger conurbations in the European Union. Environ. Model. Softw. 2001, 16, 399-414. [CrossRef]

4. Liang, W.; Yang, M.; Li, X.G. Interaction between agglomeration and Urban Haze pollution. Urban Probl. 2017, 9, 85-95.

5. Zhang, K.; Wang, D.F. Interaction between economic agglomeration and environmental pollution and spatial spillover. China Ind. Econ. 2014, 6, 70-82. 
6. Verhoef, E.T.; Nijkamp, P. Externalities in urban sustainability: Environment versus localization-type agglomeration externalities in a general spatial equilibrium model of a single-sector monocentric industrial city. Ecol. Econ. 2002, 40, 157-179. [CrossRef]

7. Feldman, M.P. The New Economics of Innovation, Spillovers and Agglomeration: A review of Empirical Studies. Econ. Innov. New Tech. 1999, 8, 5-25. [CrossRef]

8. Li, Q.; Song, J.P.; Zhang, J.H.; Yu, W.; Hu, H. Evolution of the Impact of Urbanization on Environmental Air Quality in China. Acta Sci. Circumst. 2013, 33, 2402-2411.

9. Han, L. Construction and Measurement of Haze Disaster Risk Index. Stat. Decis. 2017, 2, $28-32$.

10. Han, L.H.; Xiang, X.; Zhang, H.L.; Cheng, S.Y.; Lang, J.L. Insights into submicron particulate evolution, sources and influences on haze pollution in Beijing, China. Atmos. Environ. 2019, 201, 360-368. [CrossRef]

11. Zhang, B.Y.; Zhao, X.M.; Zhang, J.B. Characteristics of peroxyacetyl nitrate pollution during a 2015 winter haze episode in Beijing. Environ. Pollut. 2019, 244, 379-387. [CrossRef]

12. Pan, Y.P.; Wang, Y.S.; Zhang, J.K.; Liu, Z.R.; Wang, Y.H. Redefining the importance of nitrate during haze pollution to help optimize an emission control strategy. Atmos. Environ. 2016, 141, 197-202. [CrossRef]

13. Tao, M.H.; Chen, L.F.; Xiong, X.Z.; Zhang, M.G.; Wang, Z.F. Formation process of the widespread extreme haze pollution over northern China in January 2013: Implications for regional air quality and climate. Atmos. Environ. 2014, 98, 417-425. [CrossRef]

14. Liu, D.Y.; Yan, W.L.; Kang, Z.M.; Liu, A.N.; Zhu, Y. Boundary-layer features and regional transport process of an extreme haze pollution event in Nanjing, China. Atmos. Pollut. Res. 2018, 9, 1088-1099. [CrossRef]

15. He, J.J.; Gong, S.L.; Zhou, C.H.; Lu, S.H.; Yin, C.M. Analyses of winter circulation types and their impacts on haze pollution in Beijing. Atmos. Environ. 2018, 192, 94-103. [CrossRef]

16. Zheng, Z.F.; Xu, G.R.; Yang, Y.J.; Wang, Y.T.; Li, Q.C. Statistical characteristics and the urban spillover effect of haze pollution in the circum-Beijing region. Atmos. Pollut. Res. 2018, 9, 1062-1071. [CrossRef]

17. Cheng, X.G.; Richard, B.; Zhao, T.L.; Xu, X.D.; Shang, K. Climate modulation of Nio 3.4 SST-anomalies on air quality change in southern China: Application to seasonal forecast of haze pollution. Atmos. Res. 2019, 225, 157-164. [CrossRef]

18. Li, T.Y.; Deng, X.J.; Li, Y.; Song, Y.S.; Wang, C.L. Transport paths and vertical exchange characteristics of haze pollution in Southern China. Sci. Total Environ 2018, 625, 1074-1087. [CrossRef]

19. Zhang, L.; Guo, X.M.; Zhao, T.L.; Gong, S.L. A modelling study of the terrain effects on haze pollution in the Sichuan Basin. Atmos. Environ. 2019, 196, 77-85. [CrossRef]

20. Liu, H.J.; Du, G.J. Spatial correlation study of haze pollution in China. Stat. Res. 2018, 319, 5-17.

21. Wang, C.C.; Wang, Y.C.; Ma, R.F.; Wang, J.M. Spatial Econometric Study on the Impact of Economic Agglomeration on Haze Pollution: A Case Study of the Yangtze River Delta. Res. Environ. Yangtze Bas. 2019, 28, 1-11.

22. Liu, H.J.; Pei, Y.F. Environmental Kuznets Curve Test of Haze Pollution in China. Stat. Res. 2017, 3, 47-56.

23. Du, G.; Liu, S.Z.; Lei, N.; Huang, Y. A test of environmental Kuznets curve for haze pollution in China: Evidence from the penal data of 27 capital cities. J. Clean. Prod. 2018, 205, 821-827. [CrossRef]

24. Hui, L.R.; Liu, X.G.; Tan, Q.W.; Feng, M.; Cheng, N.L. VOC characteristics, sources and contributions to SOA formation during haze events in Wuhan, Central China. Sci. Total Environ. 2019, 650, 2624-2639. [CrossRef]

25. Yin, S.; Wang, X.F.; Zhang, X.R.; Zhang, Z.X.; Sun, Z.Y. Exploring the effects of crop residue burning on local haze pollution in Northeast China using ground and satellite data. Atmos. Environ. 2019, 199, $189-201$. [CrossRef]

26. Hong, Y. Evaluation of regional haze level in China based on structural equation model. Stat. Decis. 2019, 35, 62-65.

27. Tian, M.; Wang, Y.L. The relationship between industrial structure, energy consumption and the main components of haze-Take Beijing as an example. Econ. Pro. 2018, 467, 56-64.

28. Wu, J.N.; Qin, C.; Zhang, P. Influencing factors of haze pollution: An empirical study based on monitoring $\mathrm{PM}_{2.5}$ concentration in cities in China. Admin. Tri. 2016, 23, 62-66.

29. Sun, H.X.; Li, S. Spatial Coupling Relations of Atmospheric Haze with Coal Consumption and Environmental Taxation-Taking 31 Provinces and Regions in China as an Example. Inq. Econ. Iss. 2018, 1, 155-166.

30. Liang, W.; Yang, M. Urbanization, economic growth and environmental pollution: Evidence from China. Sustain. Comput. Inform. Syst. 2019, 21, 1-9. [CrossRef] 
31. Yuan, M.; Huang, Y.P.; Shen, H.F.; Li, T.W. Effects of urban form on haze pollution in China: Spatial regression analysis based on $\mathrm{PM}_{2.5}$ remote sensing data. Appl. Geogr. 2018, 98, 215-223. [CrossRef]

32. Huang, W.Q.; Fan, H.B.; Qiu, Y.F.; Cheng, Z.Y. Causation mechanism analysis for haze pollution related to vehicle emission in Guangzhou, China by employing the fault tree approach. Chemosphere 2016, 151, 9-16. [CrossRef] [PubMed]

33. Huang, W.Q.; Fan, H.B.; Qian, Y. Modeling and efficient quantified risk assessment of haze causation system in China related to vehicle emissions with uncertainty consideration. Sci. Total Environ. 2019, 668, 74-83. [CrossRef] [PubMed]

34. Li, H.; Duan, F.K.; Ma, Y.L.; He, K.B.; Kimoto, T. Case study of spring haze in Beijing: Characteristics, formation processes, secondary transition, and regional transportation. Environ. Pollut. 2018, 242, 544-554. [CrossRef] [PubMed]

35. Zhang, M.; Li, H. New evolutionary game model of the regional governance of haze pollution in China. Appl. Math. Model. 2018, 63, 577-590. [CrossRef]

36. Shen, L.; Wang, Y.Y. Supervision mechanism for pollution behavior of Chinese enterprises based on haze governance. J. Clean. Prod. 2018, 197, 571-582. [CrossRef]

37. Jia, S.W.; Liu, X.L.; Yan, G.L. Effect of APCF policy on the haze pollution in China: A system dynamics approach. Energy Policy 2019, 125, 33-44. [CrossRef]

38. Hsiao, Y.L.; Chen, Y.S. Pricing the haze option with the $\mathrm{PM}_{2.5}$ index. Asia Pac. Manag. Rev. 2019, $24,27-36$. [CrossRef]

39. Norgaard, K.M. Cognitive and Behavioral Challenges in Responding to Climate Change. Policy Res. Work. Paper 2016, 4940, 76-85.

40. Zhao, C.N.; Zhang, M.; Wang, W.W. Exploring the influence of severe haze pollution on residents' intention to purchase energy-saving appliances. J. Clean. Prod. 2019, 212, 1536-1543. [CrossRef]

41. Zhang, M.; Guo, S.; Bai, C.Y.; Wang, W.W. Study on the impact of haze pollution on residents' green consumption behavior: The case of Shandong Province. J. Clean. Prod. 2019, 219, 11-19. [CrossRef]

42. Guan, Y.M.; Li, P.; Jiao, Y. Property rights, haze pollution and low-carbon performance of enterprises. Jiangsu Soc. Sci. 2018, 296, 91-100.

43. Dong, T.T. Study on the Interaction of Haze Pollution $\left(\mathrm{PM}_{2.5}\right)$, Industrial Agglomeration and Industrial Efficiency. Soft Sci. 2016, 30, 26-30.

44. Lin, L.; Zhu, X.; Jiang, G.R. The influence of haze on the growth rate of regional GDP: The mediating effect of depression. J. Psychol. Sci. 2018, 233, 117-122.

45. Andersson, M.; Modig, L.; Hedman, L. Heavy vehicle traffic is related to wheeze among schoolchildren: A population-based study in an area with low traffic flows. J. Environ. Health 2011, 10, 91. [CrossRef]

46. Leem, J.H.; Kaplan, B.M.; Shim, Y.K. Exposures to Air Pollutants during Pregnancy and Preterm Delivery. Environ. Health Perspect. 2006, 114, 905-910. [CrossRef]

47. Briggs, D.J.; Elliott, P. The use of geographical information systems in studies on environment and health. World Health Stat. Q. 1995, 48, 85-94.

48. Sorensen, M.; Hoffmann, B.; Hvidberg, M. Long-Term Exposure to Traffic-Related Air Pollution Associated with Blood Pressure and Self-Reported Hypertension in a Danish Cohort. Environ. Health Perspect. 2012, 120, 418-424. [CrossRef]

49. Moore, D.K.; Jerrett, M.; Mack, W.J.; Künzli, N. A land use regression model for predicting ambient fine particulate matter across Los Angeles, CA. J. Environ. Monit. 2007, 9, 246-252. [CrossRef]

50. Famoso, F.; Wilson, J.; Monforte, P.; Lanzafame, R.; Brusca, S.; Lulla, V. Measurement and modeling of ground-level ozone concentration in Catania, Italy using biophysical remote sensing and GIS. Int. J. Appl. Eng. Res. 2017, 12, 12.

51. Wang, S.; Liao, T.T.; Wang, L.L.; Sun, Y. Process analysis of characteristics of the boundary layer during a heavy haze pollution episode in an inland megacity. China J. Environ. Sci. 2016, 40, 138-144. [CrossRef] [PubMed]

52. Dong, F.; Zhang, S.N.; Long, R.Y.; Zhang, X.Y.; Sun, Z.Y. Determinants of haze pollution: An analysis from the perspective of spatiotemporal heterogeneity. J. Clean. Prod. 2019, 222, 768-783. [CrossRef]

53. Lin, C.H. Spatial econometric analysis of haze pollution in China. Stat. Decis. 2018, 34, 94-99.

54. Zhou, J.K.; Huang, J.; Zhang, Y.N. Main Practices and Enlightenment of Foreign Policies Supporting Technological Innovation of Haze Prevention and Control. Sci. Technol. Manag. Res. 2018, 38, 46-52. 
55. Xu, B.; Luo, L.Q.; Lin, B.Q. A dynamic analysis of air pollution emissions in China: Evidence from nonparametric additive regression models. Ecol. Indic. 2016, 63, 346-358. [CrossRef]

56. Singh, N.; Murari, V.; Kumar, M.; Barman, S.C.; Banerjee, T. Fine particulates over South Asia: Review and meta-analysis of $\mathrm{PM}_{2.5}$ source apportionment through receptor model. Environ. Pollut. 2017, 223, 121-136. [CrossRef]

57. Zhou, M.T.; Wang, Z. Will the disclosure of air quality information affect urban housing prices?-Natural experiments based on the public $\mathrm{PM}_{2.5}$ monitoring data in cities of China. World Eco. Paper 2018, 244, $24-46$.

58. Hu, Z.Q.; Miao, C.H. Spatial-temporal pattern of pollution industry transfer in China and its relationship with pollution transfer. Soft Sci. 2018, 32, 39-43.

59. Dong, S.C.; Shi, D.; Li, F.J. The Situation of Resources, Environment, Economy and Urbanization in Central China and the Strategy of Green Rise. Resour. Sci. 2019, 41, 35-44.

60. Wang, L.F.; Zhang, J.R. Spatial econometric analysis of the impact of urbanization on environmental quality in China. Stat. Decis. 2018, 503, 88-91.

61. Liu, H.M.; Fang, C.L.; Zhang, X.L.; Wang, Z.Y.; Li, F.Z. The effect of natural and anthropogenic factors on haze pollution in Chinese cities: A spatial econometrics approach. J. Clean. Prod. 2017, 165, 323-333. [CrossRef]

62. Liu, C.Y.; Xu, Y.Z. How Environmental Regulations Affect Haze Pollution Control?-An Empirical Study Based on Intermediate Effect. J. China Univ. Geosci. 2017, 6, 47-59.

(C) 2019 by the authors. Licensee MDPI, Basel, Switzerland. This article is an open access article distributed under the terms and conditions of the Creative Commons Attribution (CC BY) license (http://creativecommons.org/licenses/by/4.0/). 